\title{
Prevalência, quantificação e resistência a antimicrobianos de sorovares de Salmonella isolados de lingüiça frescal suína
}

\author{
Prevalence, quantification, and antimicrobial drug resistance \\ of Salmonella serovars isolated from fresh pork sausage
}

\section{Denis Augusto SPRICIGO ${ }^{1 \star}$, Suzana Ribeiro MATSUMOTO ${ }^{1}$, Misael Leopoldo ESPÍNDOLA ${ }^{1}$, Sandra Maria FERRAZ ${ }^{1}$}

\section{Resumo}

A Salmonella sp. é uma das principais causas mundiais de toxinfecção alimentar. Nos últimos anos, as preocupações têm se voltado para a carne e produtos suínos tanto no aspecto de saúde pública como na sua comercialização/exportação. O presente estudo tem como objetivos: 1) verificar a prevalência de sorovares de Salmonella sp. em lingüiças tipo frescal de matéria-prima suína comercializadas em Lages (SC), bem como o seu nível de contaminação; e 2) verificar o perfil de resistência aos antimicrobianos destes isolados. Para tanto, foram coletadas 200 amostras de nove marcas, em diferentes estabelecimentos comerciais. Foram isoladas Salmonella sp. em 27\% (54), sendo o sorovar Derby o mais encontrado. Apenas uma amostra apresentou uma concentração de microorganismos maior que 1,100 NMP.g ${ }^{-1}$, valor normalmente tido como necessário para causar infecção por Salmonella do grupo não-tifóide. Posteriormente, os 60 isolados foram submetidos ao teste de susceptibilidade in vitro, frente a 14 antimicrobianos. Entre esses isolados, 56,67\% apresentaram resistência a pelo menos um dos antimicrobianos testados e o perfil de multirresistência foi encontrado em $20 \%$. A prevalência elevada de produtos positivos para Salmonella sp. pode representar um risco ao consumidor, principalmente considerando-se o alto número de isolados resistentes encontrado neste estudo.

Palavras-chave: Salmonella sp.; lingüiça frescal suína; quantificação; resistência antimicrobiana; multirresistência.

\begin{abstract}
Salmonella sp. is one of the main causes of food poisoning. In the last years, the main focus has been on beef and swine products because of both public health concerns and commercialization/exportation. This study was conducted in order to: 1) verify the prevalence of Salmonella serovars in fresh pork sausages commercialized in Lages, state of Santa Catarina and analyze its level of contamination; and 2) determine the profile of antimicrobial resistance of Salmonella sp. isolates. For this purpose, 200 samples of nine brands were collected from different commercial stores. Salmonella sp. was isolated from 27\% (54). Serovar Derby accounted for the highest percentage of isolates. Only one sausage sample had a quantity of microorganism higher than $1.100 \mathrm{MPN} \cdot \mathrm{g}^{-1}$. This microorganism concentration is considered enough to cause a nontyphoidal Salmonella infection. Later, the 60 strains were tested against 14 antimicrobials. Among them, 56,67\% showed resistance to at least one antimicrobial agent and $20 \%$ showed multi-resistance. The Salmonella sp. prevalence in the products may be a risk for the consumer, mainly considering the high number of antimicrobial resistant isolates found in the study.

Keywords: Salmonella sp.; fresh pork sausage; quantification; antimicrobial resistance; multiresistance.
\end{abstract}

\section{Introdução}

Ao longo do tempo, as aves e seus produtos derivados ocuparam maior importância como fonte de infecção por Salmonella enterica em humanos (BAGGESEN; WEGENER, 1994; OLSEN et al., 1992). Porém, nos últimos anos, os suínos e seus derivados também vêm se tornando fonte dessa infecção, crescendo com destaque nos casos de salmonelose transmitida por produtos de origem animal. Em países desenvolvidos, a carne suína já é responsável por 5-30\% dos casos (BERENDS et al., 1998).

A crescente demanda de derivados suínos tipo frescal representa um aumento do risco destes produtos participarem de surtos de salmonelose em humanos (CASTAGNA et al., 2004). Dentre os derivados, a lingüiça apresenta um maior risco, pois pode ocorrer contaminação e proliferação dos microorganismos durante o preparo, a manufatura e o estoque do produto (GIOVANNINI et al., 2004). Além disso, trabalhos recentes comprovaram a relação da presença de Salmonella sp. nos linfonodos submandibulares e tonsilas, que ficam agregados à massa de embutidos, e no conteúdo intestinal de suínos ao abate, com o isolamento de microorganismos no produto final (CASTAGNA et al., 2004).

Geralmente, somente é pesquisada a presença de Salmonella sp. nos alimentos, não se levando em consideração a quantidade do patógeno. Esse fator quantitativo determina, juntamente com a condição de saúde do indivíduo, o risco da infecção. No Brasil, apenas os estados do Rio de Janeiro, Rio Grande do Sul,

Recebido para publicação em 19/4/2007

Aceito para publicação em 2/10/2008 (002471)

${ }^{1}$ Centro de Ciências Agroveterinárias - CAV, Laboratório de Microbiologia Veterinária, Departamento de Medicina Veterinária Preventiva e Tecnologia - DMVTP,

Universidade do Estado de Santa Catarina - UDESC, Av. Luís de Camões, 2090, CEP 88520-000, Lages - SC, Brasil, E-mail: denispricigo@bol.com.br

${ }^{*}$ A quem a correspondência deve ser enviada 
Mato Grosso e Paraná apresentam algum tipo de análise de prevalência de Salmonella sp. em produtos cárneos de origem suína (CHAVES et al., 2000; LOGUERCIO et al., 2002; REIS et al., 1995; GALARDA et al., 1999). Apesar da importância dos frigoríficos catarinenses na produção e exportação destes produtos, existe apenas um estudo prévio, com baixa amostragem, determinando a prevalência e sorovares do microorganismo em embutidos frescais suínos produzidos no estado de Santa Catarina (MATSUMOTO et al., 2006).

A salmonelose em humanos é caracterizada primariamente por uma gastroenterite e não requer, na maioria das vezes, o tratamento com antimicrobianos. Porém, este procedimento é essencial quando há febre entérica, salmonelose invasiva e pacientes com risco de doença extraintestinal, principalmente em crianças e portadores do vírus da imunodeficiência humana (PARRY, 2003).

Desde o início dos anos 90, tem ocorrido um aumento drástico na resistência da Salmonella enterica aos antimicrobianos. Esse fato tem sido atribuído ao uso destes na profilaxia e terapêutica de animais destinados à produção de alimentos (THRELFALL et al., 2000). Dessa forma, o uso indiscriminado de antimicrobianos pode conduzir à seleção de linhagens resistentes (BAHNSON; FEDORKA-CRAY, 1999), que chegam à população através dos alimentos de origem animal.

A crescente importância de produtos suínos frescais como possíveis fontes de contaminação por Salmonella sp. em humanos justifica o monitoramento da resistência a antimicrobianos em isolados deste microorganismo. Justifica-se, dessa forma, o duplo objetivo deste trabalho: determinar a prevalência, sorovares e nível de contaminação por Salmonella sp. e também identificar o perfil de resistência dos isolados de lingüiça frescal suína. As lingüiças comercializadas em Lages-SC constituem o objeto deste estudo.

\section{Material e métodos}

O estudo foi conduzido no Laboratório de Microbiologia do Centro de Ciências Agroveterinárias da Universidade do Estado de Santa Catarina, no período de setembro de 2005 a abril de 2006.
O número de amostras para a determinação da prevalência de lingüiças frescais suínas positivas para Salmonella sp. foi calculado levando-se em consideração uma freqüência esperada de 12,6\% (MATSUMOTO et al., 2005), com intervalo de confiança de $95 \%$. A partir desses dados, mostrou-se necessário analisar um mínimo de 170 amostras (SAMPAIO, 2002).

Foram coletadas aleatoriamente, em dez diferentes estabelecimentos comerciais (1-10) do município de Lages-SC, 200 amostras de lingüiça tipo frescal suína, de nove marcas distintas (A-I) sob inspeção federal. As amostras eram adquiridas em embalagens fechadas ou a granel. O número de amostras por marca e local não foi homogêneo devido às diferentes disponibilidades no comércio (Tabela 1).

No laboratório, as amostras foram mantidas refrigeradas $\left(4^{\circ} \mathrm{C}\right.$ ), até serem realizados todos os processamentos (isolamento e quantificação). A metodologia utilizada para o isolamento de Salmonella sp. seguiu a descrita por Michael et al. (2003), que consiste nas seguintes etapas: 1) pré-enriquecimento de $25 \mathrm{~g}$ de amostra em $225 \mathrm{~mL}$ de água peptonada tamponada; 2) enriquecimento seletivo em caldo Tetrationato de Muller Kauffmann e em caldo Rappaport Vassiliadis; e 3) isolamento em ágar verde brilhante-lactose-sacarose (BPLS) e ágar xilose lisina-tergitol 4 (XLT4).

As colônias suspeitas foram semeadas em TSI (Triple Sugar Iron Agar), LIA (Lisina Iron Agar), SIM (Sulphide Indol Motility), caldo uréia e citrato de Simmons. Os isolados com resultados compatíveis com Salmonella sp. (HOLT, 1994) foram confirmados por meio de soroaglutinação ${ }^{1}$. De cada amostra, foram encaminhadas de duas a três colônias do isolamento à Fundação Instituto Oswaldo Cruz (RJ) para a sorotipificação. A quantificação deste microorganismo foi realizada em todas as amostras positivas para Salmonella por meio da metodologia descrita por Escartín et al. apud Borowsky (2005).

O teste de susceptibilidade in vitro foi realizado pelo método da difusão em ágar Mueller-Hinton (NCCLS, 2001), utilizando-se os seguintes discos de antimicrobianos ${ }^{2}$ : ácido nalidíxico (An-30 $\mu \mathrm{g}$ ), amicacina (Am-30 $\mu \mathrm{g})$, amoxicilina/ ácido clavulânico (Ac-20/10 $\mu \mathrm{g}$ ), ampicilina (Ap-10 $\mu \mathrm{g})$, cefaclor

${ }^{1}$ Soro Salmonella Polivalente, PROBAC, São Paulo, Brasil

${ }^{2} \mathrm{DME}$, Araçatuba, São Paulo, Brasil

Tabela 1. Número de amostras de lingüiça tipo frescal suína adquiridas nos diferentes estabelecimentos comerciais de Lages/SC.

\begin{tabular}{|c|c|c|c|c|c|c|c|c|c|c|c|}
\hline \multirow[t]{2}{*}{ Estabelecimento } & \multirow[t]{2}{*}{ Tipo } & \multicolumn{9}{|c|}{ Marca } & \multirow[t]{2}{*}{ Total } \\
\hline & & $\mathrm{A}$ & $\mathrm{B}$ & $\mathrm{C}$ & $\mathrm{D}$ & $\mathrm{E}$ & $\mathrm{F}$ & G & $\mathrm{H}$ & $\mathrm{I}$ & \\
\hline 1 & Municipal & 7 & - & - & - & - & - & - & 1 & 5 & 13 \\
\hline 2 & Estadual & 9 & 11 & - & - & 3 & 3 & 4 & - & - & 30 \\
\hline 3 & Municipal & - & - & 3 & - & - & - & - & 9 & - & 12 \\
\hline 4 & Municipal & 2 & - & - & - & - & - & 5 & - & - & 7 \\
\hline 5 & Estadual & 12 & 12 & - & - & - & - & 7 & - & - & 31 \\
\hline 8 & Estadual & 9 & 9 & 6 & 1 & 4 & - & 5 & - & - & 34 \\
\hline 9 & Municipal & - & - & - & - & - & 7 & - & - & - & 7 \\
\hline 10 & Estadual & 6 & 10 & - & - & 10 & - & 10 & - & 4 & 40 \\
\hline Total & & 61 & 42 & 9 & 11 & 17 & 10 & 31 & 10 & 9 & 200 \\
\hline
\end{tabular}


(Cf-30 $\mu \mathrm{g})$, ciprofloxacina (Ci-5 $\mu \mathrm{g})$, cloranfenicol (Cl-30 $\mu \mathrm{g}$ ), cotrimoxazol (St-5 $\mu \mathrm{g}$ ), estreptomicina (Es-10 $\mu \mathrm{g}$ ), gentamicina (Ge-10 $\mu \mathrm{g})$, neomicina (Ne-30 $\mu \mathrm{g}$ ), sulfonamida (Sl-300 $\mu \mathrm{g}$ ), tetraciclina $(\mathrm{Te}-30 \mu \mathrm{g})$ e tobramicina $(\mathrm{Tb}-10 \mu \mathrm{g})$.

As análises estatísticas foram realizadas por meio do teste Qui-quadrado, com nível de significância de 0,05 do pacote estatístico SAS (1999).

\section{Resultados e discussão}

As amostras de lingüiça frescal suína, analisadas neste trabalho, apresentaram uma prevalência de Salmonella sp. de $27 \%$. Este índice é mais elevado do que foi observado em estudo prévio (12,5\%), conduzido na mesma região (MATSUMOTO et al., 2006). Apenas em uma das marcas testadas (C), não foi encontrado o microorganismo. A marca B, uma das mais disponíveis no comércio e, provavelmente, uma das mais consumidas, apresentou 40,5\% de positividade (Tabela 2).

No Brasil, em estudos acerca da presença de Salmonella sp. em produtos frescais suínos, foram encontradas freqüências menores, como nos estados do Paraná (2\%), Rio de Janeiro (10\%) e Rio Grande do Sul (11,82\%) (GALARDA et al., 1999; CHAVES et al., 2000; LOGUERCIO et al., 2002). Por outro lado, no estado de Mato Grosso, foi encontrada uma prevalência de $35,3 \%$ em lingüiças frescais (REIS et al., 1995). Estudos recentes, realizados no Rio Grande do Sul, encontraram 93,94\% de amostras de massa para embutidos contaminadas por Salmonella sp. (CASTAGNA et al., 2004). A diferença nestas freqüências pode estar relacionada a vários fatores, como diferentes metodologias utilizadas para o isolamento e a própria região.

Estatisticamente, não houve diferença significativa na prevalência de Salmonella sp. entre as marcas analisadas $(\mathrm{p}=0,1134)$, os locais de compra $(\mathrm{p}=0,3421)$ e os produtos comercializados em embalagens fechadas e a granel $(p=0,1413)$. Para a primeira análise, foi excluída a marca $C$, pois esta não apresentou nenhuma amostra positiva. Devido ao número de amostras, para a comparação entre freqüências de embalagens fechadas e a granel, somente foram utilizadas aquelas marcas que se encontravam disponíveis nas duas apresentações, em número significativo (A, F e G). Seguiu-se o mesmo parâmetro para a análise dos produtos segundo o local de compra (A, B e G; 2, 5, 8 e 10).

$\mathrm{Na}$ medida em que não foi constatada diferença entre as duas apresentações do produto e entre os diferentes estabelecimentos comerciais, provavelmente a maior parte da contaminação teve origem no frigorífico ou na granja. Em um estudo conduzido na Holanda, a baia de espera foi considerada a fonte de contaminação mais importante para os animais oriundos de rebanhos soronegativos, enquanto que a granja contribuiu mais com a contaminação de carcaças de suínos provenientes de rebanhos soropositivos (SWANENBURG et al., 2001).

Mostrou-se importante determinar se a composição da lingüiça influenciaria na prevalência do microorganismo e, dessa forma, as lingüiças foram agrupadas em lombo/pernil e toscana/ outras. De forma similar às análises anteriores, devido ao número de amostras, somente foram consideradas as marcas que apresentavam os dois grupos em número suficiente (marcas A, B e E).

Foi encontrada diferença significativa $(p=0,05)$ conforme a composição da lingüiça, o que pode ser explicado pela menor possibilidade de contaminação das partes nobres dos suínos. Este fato se dá por dois motivos básicos: as partes nobres encontram-se mais elevadas na carcaça suspendida, o que dificulta a contaminação por extravasamento de conteúdo intestinal, e principalmente por essas partes serem menos manipuladas, já que esses produtos são compostos basicamente por lombo ou pernil. Deve-se ressaltar que as lingüiças toscana/outras, que formam o outro grupo, são compostas por retalhos de diversos cortes. Porém, para a confirmação desta hipótese seria necessária a realização de uma maior amostragem de produtos de mesma marca e composição distinta.

Foi encontrada ainda uma grande diversidade de sorovares (13), tanto em amostras de marcas diferentes como de marcas iguais. No entanto, em apenas seis amostras (B3, B6, E1, E3, E6 e G7) foram identificados mais de um sorovar (Tabela 3). Escartín et al. (2000) encontraram uma diversidade semelhante de Salmonella sp. isoladas de carne suína crua. Isto pode ocorrer devido a diferentes origens de contaminação, relacionadas tanto com os sorovares presentes nos lotes, quanto com possíveis contaminações cruzadas durante o processamento (CASTAGNA et al., 2004).

Similarmente a outros estudos com produtos de origem suína (CASTAGNA et al., 2004; GIOVANNINI et al., 2004;

Tabela 2. Número de amostras positivas e freqüência de Salmonella sp. em lingüiças tipo frescal suína de diferentes marcas comercializadas em Lages/SC.

\begin{tabular}{|c|c|c|c|c|c|c|c|}
\hline \multirow[t]{2}{*}{ Marca } & \multicolumn{3}{|c|}{ Positivas } & \multicolumn{3}{|c|}{ Total } & \multirow[t]{2}{*}{ Freqüência (\%) } \\
\hline & Fechadas & A granel & Total & Fechadas & A granel & Total & \\
\hline A & 1 & 10 & 11 & 8 & 53 & 61 & 18,0 \\
\hline B & 1 & 16 & 17 & 1 & 41 & 42 & 40,5 \\
\hline $\mathrm{C}$ & 0 & 0 & 0 & 9 & 0 & 9 & 0 \\
\hline $\mathrm{D}$ & 5 & 0 & 5 & 11 & 0 & 11 & 45,4 \\
\hline $\mathrm{E}$ & 7 & 0 & 7 & 17 & 0 & 17 & 41,2 \\
\hline $\mathrm{F}$ & 2 & 2 & 4 & 8 & 2 & 10 & 40,0 \\
\hline G & 4 & 2 & 6 & 6 & 25 & 31 & 19,3 \\
\hline $\mathrm{H}$ & 0 & 2 & 2 & 0 & 10 & 10 & 20,0 \\
\hline I & 2 & 0 & 2 & 9 & 0 & 9 & 22,2 \\
\hline Total & 22 & 32 & 54 & 69 & 131 & 200 & 27 \\
\hline
\end{tabular}


MATSUMOTO et al., 2006), entre os sorovares mais encontrados figuraram Typhimurium (11/60-18,33\%) e Derby (12/60-20\%). Apesar de todos os sorovares de Salmonella sp. serem considerados potencialmente patogênicos para humanos, a maioria dos surtos têm sido relacionados com maior freqüência aos sorovares Enteritidis e Typhimurium. No Brasil, os sorovares Typhimurium, Agona, Infantis e Enteritidis foram identificados em casos de infecção alimentar em humanos, sendo que, nos últimos anos, o sorovar Enteritidis tem sido o mais encontrado (TAUNAY et al., 1996; ESPER et al., 1998; JAKABI et al., 1999).

Apenas uma amostra (D5) apresentou uma quantidade de microorganismos maior que $1,100 \mathrm{NMP}^{-1}$ (Tabela 3). A dose resposta para a infecção por Salmonella do grupo não-tifóide em humanos saudáveis é de $10^{5}$ a $10^{10}$, apesar de existirem registros de surtos com doses menores que $10^{3}$ (BLASER; NEWMAN, 1982). Independentemente da quantidade do microorganismo encontrada no alimento, a legislação brasileira requer a ausência deste patógeno em $25 \mathrm{~g}$ de amostra analisada (ANVISA, 2001).

No país, existe somente um estudo de quantificação deste patógeno em produtos suínos. Neste estudo, em massas para em- butidos, foram encontradas quantidades baixas ( $<150{\left.\mathrm{NMP} . \mathrm{g}^{-1}\right)}^{-1}$ de Salmonella sp. (CASTAGNA et al., 2004). Porém, é preciso considerar que a estocagem inadequada pode permitir a multiplicação do microorganismo e este atingir a dose infectante (SOJKA; GITTER, 1961). Além disso, o risco de surtos pode estar relacionado a alimentos crus contaminados por embutidos frescais, no momento do preparo, e não propriamente por estes, que geralmente são tratados pelo calor antes do consumo (ESCARTÍN et al., 2000; GORMAN et al., 2002).

Dos 60 isolados de Salmonella sp., 34 (56,67\%) apresentaram resistência a pelo menos um dos antimicrobianos testados. Além disso, 20\% (12/60) apresentaram multirresistência, ou seja, foram resistentes a quatro ou mais antimicrobianos. Castagna (2004) encontrou índices mais elevados em um estudo de perfil de resistência, utilizando amostras provenientes de massa para embutidos tipo frescal suíno: $77,17 \%$ das amostras apresentaram resistência a pelo menos um antimicrobiano e $27,6 \%$, perfil de multirresistência.

Os maiores índices de resistência foram apresentados frente à sulfonamida (45\%) e à tetraciclina (41,67\%), enquanto nenhuma amostra foi resistente a amoxicilina/ácido clavulânico, cefaclor, gentamicina, neomicina e tobramicina (Tabela 4). Em

Tabela 3. Amostras de lingüiça tipo frescal suína positivas para Salmonella sp. com seus respectivos sorovares e Número Mais Provável por Grama (NMP.g $\left.{ }^{-1}\right)$.

\begin{tabular}{|c|c|c|c|c|c|}
\hline Amostra & Sorovar & NMP.g $^{-1}$ & Amostra & Sorovar & NMP.g $^{-1}$ \\
\hline A1 & Schwarzengrund & 3,6 & D1 & Typhimurium & 9,2 \\
\hline A2 & Schwarzengrund & $<3,0$ & D2 & Panama & 15 \\
\hline A3 & Schwarzengrund & 43 & D3 & Derby & 93 \\
\hline A5 & Derby & 9,2 & D5 & Typhimurium & $>1.100$ \\
\hline A6 & Derby & $<3,0$ & E1 & (O3,10:h:-) & 3,6 \\
\hline A9 & Bredeney & $<3,0$ & E3 & (O3,10:h:-) & 20 \\
\hline $\mathrm{A} 10$ & Agona & $<3,0$ & E3 & London & - \\
\hline A11 & Typhimurium & 9,2 & $\mathrm{E} 4$ & Derby & $<3,0$ \\
\hline $\mathrm{B} 1$ & Brandenburg & $<3,0$ & E5 & Rissen & 460 \\
\hline B2 & Panama & $<3,0$ & E6 & Rissen & 21 \\
\hline B6 & Agona & $<3,0$ & F3 & Anatum & 3,6 \\
\hline B6 & Derby & - & $\mathrm{F} 4$ & Anatum & 3,6 \\
\hline B7 & Brandenburg & 11 & G5 & Brandenburg & 15 \\
\hline B8 & Derby & 3,6 & G6 & Infantis & 3,6 \\
\hline B9 & Typhimurium & 9,4 & G7 & Rugosa & 3,6 \\
\hline $\mathrm{B} 10$ & Infantis & $<3,0$ & G7 & Typhimurium & - \\
\hline B11 & Infantis & $<3,0$ & G8 & Typhimurium & $<3,0$ \\
\hline $\mathrm{B} 12$ & Agona & $<3,0$ & G9 & Typhimurium & $<3,0$ \\
\hline B13 & Bredeney & $<3,0$ & G10 & Infantis & $<3,0$ \\
\hline B14 & Typhimurium & $<3,0$ & $\mathrm{H} 1$ & Schwarzengrund & $<3,0$ \\
\hline
\end{tabular}


Spricigo et al.

Tabela 4. Resistência a antimicrobianos de sorovares de Salmonella isolados de lingüiças tipo frescal suína comercializadas em Lages/SC.

\begin{tabular}{|c|c|c|c|c|c|c|c|c|c|c|c|c|c|c|c|}
\hline \multirow[t]{2}{*}{ Sorovares } & \multirow[b]{2}{*}{$\mathrm{N}$} & \multicolumn{14}{|c|}{ Número de amostras resistentes } \\
\hline & & AN & $\mathrm{AC}$ & $\mathrm{AM}$ & $\mathrm{AP}$ & $\mathrm{CF}$ & $\mathrm{CI}$ & $\mathrm{CL}$ & ES & GE & $\mathrm{NE}$ & SL & ST & $\mathrm{TE}$ & $\mathrm{TB}$ \\
\hline Agona & 3 & - & - & - & - & - & - & - & - & - & - & 1 & - & 1 & - \\
\hline Brandenburg & 6 & 2 & - & - & - & - & - & - & - & - & - & 3 & 2 & 2 & - \\
\hline Bredeney & 2 & - & - & - & - & - & - & - & - & - & - & - & - & - & - \\
\hline Cerro & 1 & - & - & - & - & - & - & - & - & - & - & 1 & - & - & - \\
\hline Heidelberg & 1 & - & - & - & - & - & - & - & - & - & - & 1 & - & - & - \\
\hline Infantis & 5 & - & - & - & - & - & - & - & - & - & - & - & - & - & - \\
\hline London & 1 & - & - & - & - & - & - & - & - & - & - & - & - & - & - \\
\hline Panama & 4 & 2 & - & - & - & - & - & 1 & - & - & - & 1 & - & 1 & - \\
\hline Rissen & 2 & - & - & - & - & - & - & - & - & - & - & - & - & - & - \\
\hline Total & 60 & 11 & - & 2 & 5 & - & 1 & 8 & 9 & - & - & 27 & 7 & 25 & - \\
\hline
\end{tabular}

$\mathrm{N}$ = número de amostras por sorovar; $\mathrm{NA}=$ ácido nalidíxico; $\mathrm{AC}=$ amoxicilina/ácido clavulânico; $\mathrm{AM}=$ amicacina; $\mathrm{AP}=$ ampicilina; $\mathrm{CF}=$ cefaclor; $\mathrm{CI}=$ ciprofloxacina; $\mathrm{CL}=$ cloranfenicol; $\mathrm{ES}=$ estreptomicina $\mathrm{GE}=$ gentamicina; $\mathrm{NE}=$ neomicina; $\mathrm{SL}=$ sulfonamida; $\mathrm{ST}=$ cotrimoxazol; $\mathrm{TE}=$ tetra ciclina; $\mathrm{e} \mathrm{TB}=$ tobramicina.

um estudo realizado em Santa Catarina, com 582 isolados de Salmonella sp. de granjas de terminação e frigorífico, a maior resistência foi frente à tetraciclina $(78,9 \%)$ e, diferentemente do presente trabalho, encontrou-se um índice alto de resistência para a gentamicina (38\%) (KICH et al., 2006).

$\mathrm{O}$ aumento da resistência bacteriana a antimicrobianos tem sido associado a sua administração excessiva a animais criados para a produção de alimentos (CRUCHAGA et al., 2001; SCHWARZ; CHASLUS-DANCLA, 2001; TEUBER, 2001). Além disso, os maiores índices de resistência ocorrem frente a antimicrobianos disponíveis há mais tempo no mercado e que são comumente utilizados na terapêutica (BAHNSON; FEDORKA-CRAY, 1999; FEDORKA-CRAY et al., 1999; HARVEY et al., 1999). Desta forma, o alto número de amostras resistentes à tetraciclina e à sulfonamida poderia ser explicado pelo uso freqüente destes antimicrobianos nos animais.

Um isolado do sorovar Schwarzengrund foi o que apresentou resistência ao maior número de antimicrobianos testados (7/14), com o perfil AnApCiClStSlTe. Porém, o sorovar Typhimurium foi o que apresentou maior número de isolados multirresistentes (5/12-41,67\%). Linhagens deste sorovar pertencentes ao fagotipo DT104 são considerados como de maior patogenicidade para humanos (BAGGESEN; AARESTRUP, 1998; NIELSEN et al., 1999), e tem se caracterizado, em diversos países, por um perfil de resistência contra ampicilina, tetraciclina, estreptomicina, cloranfenicol e sulfonamidas (THRELFALL et al., 1994). No presente trabalho, nenhum dos isolados de Typhimurium apresentou este perfil. No entanto, quatro apresentaram padrões semelhantes, três com ClEsSlTe e um com ApClEsTe.

Estas cepas multirresistentes podem caracterizar um risco a saúde do consumidor. Surtos causados por elas podem repre- sentar uma barreira para o sucesso do tratamento, aumentando o custo deste e a mortalidade na população de risco. A antibioticoterapia não é necessária em casos usuais de salmonelose, entretanto nas infecções generalizadas e em pacientes de risco o tratamento precisa ser instituído (PARRY, 2003).

Apesar de o perfil de resistência a antimicrobianos não ser considerado a melhor opção para demonstrar o grau de similaridade entre linhagens bacterianas, perfis idênticos dentro de um mesmo sorovar de salmonelas podem indicar a presença de clones (LIMPITAKIS et al., 1999). Neste estudo, foram encontrados 18 perfis de resistência. Poucos foram os casos de determinados sorovares apresentarem o mesmo perfil e, quando isto ocorreu, as amostras tinham origens distintas. Seria necessária a realização de outras técnicas, como fagotipificação e eletroforese em campo pulsado, para uma melhor discriminação entre os isolados (BESSA, 2006).

Programas de monitoramento de resistência antimicrobiana já estão sendo conduzidos em vários países. Na Dinamarca, a preocupação com a segurança do consumidor resultou na implementação de um programa, cujos objetivos principais são o controle da resistência de bactérias isoladas de animais de produção e o controle do risco da transmissão de patógenos resistentes para o homem através do alimento (MONNET et al., 2000). A resistência antimicrobiana está entre os desafios no controle da Salmonella e a vigilância, por meio de programas de monitoramento, seria um dos mecanismos para tal controle.

Apesar de as lingüiças tipo frescal suína que estão disponíveis à população de Lages apresentarem baixos níveis de contaminação por Salmonella sp., é preocupante o fato de praticamente todas a marcas analisadas apresentarem prevalências elevadas deste patógeno. Este problema, além de ser um risco para a saúde pública, pode criar entraves à comercialização dos produtos para 
países que apresentam controle do microorganismo. Com isso, faz-se necessária a implementação de um programa nacional de controle de Salmonella sp. e, para tanto, mais estudos são necessários em Santa Catarina e em outros estados produtores, contemplando outras etapas da cadeia suinícola.

\section{Conclusões}

As lingüiças tipo frescal de carne suína disponíveis no comércio de Lages, Santa Catarina, apresentam uma prevalência de $27 \%$ de isolamento de Salmonella sp. A quantificação de Salmonella sp. em amostras positivas demonstrou que o nível de contaminação encontrou-se, na maioria dos casos, abaixo da dose considerada infectante. Além disso, foi encontrado um alto número de isolados com multirresistência a antimicrobianos, o que indica a necessidade de um maior controle dos antimicrobianos utilizados na granja, para minimizar o risco de seleção e transmissão de linhagens resistentes.

\section{Agradecimentos}

À Dra. Eliane Falavina dos Reis, Departamento de Bacteriologia, Instituto Oswaldo Cruz (RJ), pela sorotipificação das amostras.

Ao Professor Sérgio Dallagnol, Laboratório de Patologia Aviária-CAV/UDESC, pelo auxílio na realização deste trabalho.

Ao Professor André Thaler Neto, pela análise estatística.

\section{Referências bibliográficas}

ANVISA. Agência Nacional de Vigilância Sanitária. Resolução-RDC $\mathbf{n}^{\mathbf{0}}$ 12, de 02 de janeiro de 2001. Disponível em: <http://e-legis. anvisa.gov.br/leisref/public/showAct.php?id=144>. Acesso em: 20 Nov. 2006.

BAGGESEN, D. L.; WEGENER, H. C. Phage types of Salmonella enterica ssp. enterica serovar Typhimurium isolated from production animals and humans in Denmark. Acta Veterinaria Scandinavica, v. 35, n. 4, p. 349-354, 1994.

BAGGESEN, D. L.; AARESTRUP, F. Characterization of recently emerged multiple antibiotic resistant Salmonella enterica serovar Typhimurium DT104 and other multiresistant phage types from Danish pig herds. Veterinary Record, v. 143, n. 4, p. 95-97, 1998.

BAHNSON, B. P.; FEDORKA-CRAY, P. J. The association of antimicrobial resistance pattern and reported usage of antimicrobials in commercial growing pig production. In: INTERNATIONAL SYMPOSIUM OM THE EPIDEMIOLOGY AND CONTROL OF SALMONELLA IN PORK, 3, 1999, Washington. Proceedings... Washington, 1999. p. 240-241.

BERENDS, B. R.; VAN KNAPEN, F.; MOSSEL, D. A. A. et al. Impact on human health of Salmonella spp. on pork in The Netherlands and the anticipated effects of some currently proposed control strategies. International Journal of Food Microbiology, v. 44, n. 3, p. 219-229, 1998

BESSA, M. C. Caracterização fenotípica e genotípica de amostras de Salmonella enterica sorovar Typhimurium isoladas de suínos no Rio Grande do Sul. Porto Alegre, 2006. 145p. Tese - (Doutorado em Ciências Veterinárias), Curso do Programa de Pós-graduação em Ciências Veterinárias, Universidade Federal do Rio Grande do Sul.
BLASER, M. J.; NEWMAN, L. S. A review of human samonellosis: I. Infective dose. Journal of Infections Diseases, v. 4, p. 1096-1106, 1982.

BOROWSKY, L. M. Comparação de dois métodos de quantificação de Salmonella sp. em embutidos suínos. Porto Alegre, 2005. 56p. Dissertação - (Mestrado em Bacteriologia), Curso do Programa de Pós-graduação em Ciências Veterinárias, Universidade Federal do Rio Grande do Sul.

CASTAGNA, S. M. F. Associação da prevalência de suínos portadores de Salmonella sp. ao abate e a contaminação de embutidos tipo frescal. Porto Alegre, 2004. 110 p. Tese - (Doutorado em Ciências Veterinárias na área de Bacteriologia), Curso de Pós-graduação em Ciências Veterinárias, Universidade Federal do Rio Grande do Sul.

CASTAGNA, S. M. F.; SCHWARZ, P.; CANAL, C. W. et al. Prevalência de suínos portadores de Salmonella sp. ao abate e contaminação de embutidos tipo frescal. Acta Scientiae Veterinariae, v. 32, n. 2, p. 141-147, 2004.

CHAVES, G. M. C.; GONÇALVES, P. M. R.; FRANCO, R. M. et al. Avaliação bacteriológica de lingüiça frescal suína comercializada no município do Rio de Janeiro, RJ. Higiene Alimentar, v. 14, n. 13, p. 48-52, 2000.

CRUCHAGA, S.; ECHEITA, A.; ALADUEÑA, A. et al. Antimicrobial resistance in Salmonellae from humans, food and animals in Spain in 1998. Journal of Antimicrobial Chemotherapy, v. 47, n. 3, p. 315-321, 2001.

ESCARTÍN, E. F.; LOZANO, J. S.; GARCÍA, O. R. Quantitative survival of native Salmonella serovars during storage of frozen raw pork. International Journal of Food Microbiology, v. 54, n. 1, p. 19-25, 2000.

ESPER, M. R. N. R.; FREITAS, A. M.; FERNANDES, S. A. et al. Salmonella: Sorotipos identificados das cepas isoladas de pacientes hospitalizados e não hospitalizados, na região de Presidente Prudente, SP, no período de 1978-1997. Revista do Instituto Adolfo Lutz, v. 57, p. 45-50, 1998.

FEDORKA-CRAY, P. J.; BAHNSON, P. B.; LADELY, S. R. Antimicrobial resistance patterns of Salmonella isolates collected from slaughter age pigs. In: INTERNATIONAL SYMPOSIUM OM THE EPIDEMIOLOGY AND CONTROL OF SALMONELLA IN PORK, 3, 1999, Washington. Proceedings...Washington, p. 245-247, 1999.

GALARDA, I.; LIMA, M. L. P. S; MIKOSZEWSKA, I. et al. Pesquisa de Salmonella em produtos alimentares de origem animal. Boletim CEPPA, v. 9, n. 2, p. 170-177, 1999.

GIOVANNINI, A.; PRENCIPE, V.; CONTE, A. et al. Quantative risk assessment of Salmonella spp. infection for the consumer of pork products in an italian region. Food Control, v. 15, n. 2, p. 139-144, 2004.

GORMAN, R.; BLOOMFIELD, S.; ADLEY, C. C. A study of crosscontamination of food-borne pathogens in the domestic kitchen in the Republic of Ireland. International Journal of Food Microbiology, v. 76, n. 1, p. 143-150, 2002.

HARVEY, R. B.; FARRINGTON, L. A.; BUCKLEY, S. A. et al. Epidemiological survey of antimicrobial-resistant Salmonella in market-age swine. In: INTERNATIONAL SYMPOSIUM OM THE EPIDEMIOLOGY AND CONTROL OF SALMONELLA IN PORK, 3, 1999, Washington. Proceedings...Washington, 1999. p. 252-256.

HOLT, J.G. Bergey's Manual of Determinative Bacteriology. 9 ed. New York: Williams \& Wilkims, 1994. 787 p. 
JAKABI, M.; BUZZO, A. A.; RISTORI, C. A. et al. Observações laboratoriais sobre surtos alimentares de Salmonella sp., ocorridos na grande São Paulo, no período de 1994 a 1997. Revista Instituto Adolfo Lutz, v. 58, n. 1, p. 47-51, 1999.

KICH, J. D.; COLDEBELLA, A.; MORÉS, N. et al. Resistência antimicrobiana em isolados de Salmonella provenientes de granjas de terminação e frigorífico de Santa Catarina. In: CONGRESSO LATINO-AMERICANO DE SUINOCULTURA, 3, 2006, Foz do Iguaçu. Anais... Foz do Iguaçu, 2006. p. 461-463.

LIMPITAKIS, N. et al. Antibiotic sensitivity profile of Salmonella isolated from two slaughterhouses and human clinical cases. In: INTERNATIONAL SYMPOSIUM OM THE EPIDEMIOLOGY AND CONTROL OF SALMONELLA IN PORK, 3, 1999, Washington. Proceedings...Washington, 1999. p. 257-260.

LOGUERCIO, A. P.; ALEIXO, J. A. G.; VARGAS, A. C. et al. ELISA indireto na detecção de Salmonella spp. em lingüiça suína. Ciência Rural, v. 32, n. 6, p. 1057-1062, 2002.

MATSUMOTO, S. R.; SPRICIGO, D. A.; ESPÍNDOLA, M. L. et al. Pesquisa de Salmonella sp. em lingüiça tipo frescal de matériaprima suína disponível à população de Lages/SC. In: CICLO DE ATUALIZAÇÃO EM MEDICINA VETERINÁRIA, 12, 2006, Lages. Anais... Lages, 2006. p. 124.

MICHAEL, G.; SIMONETTI, R.; COSTA, M. et al. Comparison of different selective enrichment steps to isolate Salmonella sp. from feces of finishing swine. Brazilian Journal of Microbiology, v. 34, n. 2, p. 138-142, 2003.

MONNET, D. L.; EMBORG, H. D.; ANDERSEN, S. R. et al. Surveillance of antimicrobial resistance in Denmark. European Communicable Disease Bulletin, v. 5, n. 12, p. 129-132, 2000.

NCCLS. Performance standards for antimicrobial susceptibility testing; 11th informational supplement. Approved standard M2-A7 and M7-A5. Wayne, PA, USA: National Committee for Clinical Laboratory Standards, 2001.

NIELSEN, B.; MOGELMOSE, V.; SORENSEN, L. L. et al. Tracing back multi-resistant Salmonella Typhimurium DT104 from pork at the slaughterhouse to a specific swine herd by strategical use of serology and culture. In: INTERNATIONAL SYMPOSIUM OM THE EPIDEMIOLOGY AND CONTROL OF SALMONELLA IN PORK, 3, 1999, Washington. Proceedings...Washington, 1999. p.261-263.
OLSEN, J. E; SORENSEN, M.; BROWN, D. J. et al. Plasmid profiles as an epidemiological marker in Salmonella enterica serovar berta infections. Comparison of isolates obtained from humans and poultry. APMIS, v. 100, n. 3, p. 221-228, 1992.

PARRY, C. M. Antimicrobial drug resistance in Salmonella enterica. Current Opinion in Infectious Diseases, v. 16, n. 5, p. 467-472, 2003.

REIS, R. B.; KRUGER, C. S.; MACIEL, M. S. Salmonella spp. em produtos cárneos comercializados no município de Cuiabá- MT. Avaliação da metodologia de pesquisa. Modelos de resistência a drogas antimicrobianas. Ciência Tecnologia de Alimentos, v. 15, n. 1, p. 74-78, 1995.

SAMPAIO, I. B. M. Estatística aplicada à experimentação animal. 2 ed. Belo Horizonte: Fundação de Estudo e Pesquisa em Medicina Veterinária e Zootecnia, 2002. 265 p. (Cap. 12: Estudo de dispersão de freqüência, p. 107-121).

SAS INSTITUTE - Statistical Analysis System . SAS User Guide: Statical Analysis System. Version 8.2. Cary, NC, 1999.

SCHWARZ, S.; CHASLUS-DANCLA, E. Use of antimicrobials in veterinary medicine and mechanisms of resistance. Veterinary Research, v. 32, n. 3-4, p. 201-225, 2001.

SOJKA, W. J.; GITTER, M. Salmonellosis in pigs with reference to its public health significance. Veterinary Reviews and Annotations, v. 7, p. 11-28, 1961.

SWANENBURG, M.; BERENDS, B. R.; URLINGS, H. A. P. et al. Epidemiological investigations into the sources of Salmonella contamination of pork. Berliner und Münchener Tierärztliche Wochenschrift, v. 114, n. 9-10, p. 356-359, 2001.

TAUNAY, A. E.; FERNANDES, A. S.; TAVECHIO, A. T. et al. The role of public health laboratory in the problem of Salmonellosis in São Paulo, Brazil. Revista do Instituto de Medicina Tropical de São Paulo, v. 38, n. 2, p. 119-127, 1996.

TEUBER, M. Veterinary use and antibiotic resistance. Current Opinion in Microbiology, v. 4, n. 5, p. 493-499, 2001.

THRELFALL, E. J.; FROST, J. A.; WARD, L. R. et al. Epidemic in cattle and humans of Salmonella Typhimurium DT104 with chromosomally integrated multiple drug resistance. Veterinary Record, v. 134, n. 22, p. 577, 1994.

THRELFALL, E. J.; WARD, L. R.; FROST, J. A. et al. The emergence and spread of antibiotic resistance in food-borne bacteria. International Journal of Food Microbiology, v. 62, n. 1-2, p. 1-5, 2000. 